\title{
Projeto Integrador: espaço de aprendizagem significativa no PROEJA
}

\author{
Proyecto Integrador: Espacio de aprendizaje significativo \\ en el PROEJA \\ Multidisciplinary integrative project: a meaning full earning space \\ in PROEJA
}

\author{
Michele Moraes Lopes ${ }^{1}$ \\ Márcia Della Flora Cortes ${ }^{2}$
}

\begin{abstract}
Resumo
Este trabalho tem o objetivo de relatar uma experiência que ocorre de forma interdisciplinar no curso Técnico em Comércio na modalidade PROEJA do Instituto Federal de Educação, Ciência e Tecnologia Farroupilha Campus Júlio de Castilhos, há 6 anos, denominada Bazar Técnico em Comércio. Essa prática tem o intuito de buscar novas formas de aprendizagem na Educação Profissional Integrada à Educação Básica na Modalidade de Jovens e Adultos levando em consideração as vivências e experiências do educando que proporcionam a prática da economia solidária e fomentam o empreendedorismo. O Bazar é o momento de socialização e comercialização dos produtos produzidos nas oficinas, integrando assim educandos, educadores e comunidade. $\mathrm{O}$ curso tem como finalidade contribuir na superação da formação integral entre o pensar e o fazer, aliando a teoria à prática para oportunizar aos alunos condições de geração de renda autogestionada, através de práticas de gestão e comércio. A metodologia desse trabalho constitui-se de um estudo de caso do Bazar Técnico em Comércio bem como de relato de experiência. O projeto integrador desse curso resultou na inserção da Instituição na comunidade externa, através do trabalho integrado entre alunos, servidores e comunidade.
\end{abstract}

Palavras-chaves: Prática Interdisciplinar; Educação de adultos; Projeto Integrador.

\section{Resumen}

Este trabajo tieneel objetivo de relatar una experiencia que ocurre de forma interdisciplinariaenel curso Técnico en Comercio enlamodalidad PROEJA del Instituto Federal de Educación, Ciencia y Tecnología Farroupilha Campus Júlio de Castilhos, hace 6 años, denominada Bazar Técnico en Comercio. Esta prácticatieneel propósito de buscar nuevas formas de aprendizajeenlaEducaciónProfesional Integrada alaEducación Básica enlamodalidad de Jóvenesy Adultosteniendoencuentalas vivencias y experiencias del educando que proporcionanlapráctica de laeconomía solidaria y fomentanelespírituemprendedor.El Bazar es el momento de socialización y comercialización de losproductosproducidosenlostalleres, integrando educandos, educadores y comunidad. El curso tiene como finalidad contribuir enlasuperación de laformación integral entre el pensar y elhacer, aliando lateoría a lapráctica para oportunizar a losalumnos condiciones de generación de ingresosautogestionados, a través de prácticas de gestión y comercio. La metodología de este trabajo se constituye en un estudio de caso del Bazar Técnico en Comercio así como de relato de experiencia. El proyecto integrador de ese curso resultó en la inserción de la Institución en la comunidad externa, a través del trabajo integrado entre alumnos, servidores y comunidad.

Palabras claves: Práctica Interdisciplinaria; Educación de adultos; Proyecto Integrador.

1 Mestre em Patrimônio Cultural pela Universidade Federal de Santa Maria - UFSM; RS; Brasil; michele.lopes@iffarroupilha.edu.br

${ }^{2}$ Doutoranda em Memória Social e Patrimônio Cultural; UFPEL; Pelotas; RS; Brasil; marciadfc@yahoo.com.br 


\begin{abstract}
This work has the objective of describe an interdisciplinary activity that has been developed for the last 6 years by the students of the Technical Course of Commerce, for Youth and Adults, at the Federal Institute of Education, Science and Technology Farroupilha - Júlio de Castilhos Campus, called Technical Bazaar in Commerce. This practice aims to seek new forms of learning taking into account the experiences of the students, as it provides the practice of solidarity economy and boost entrepreneurship. The Bazaar is the moment of socialization and commercialization of the products produced in the workshops, thus integrating students, educators and the community. The course aims to contribute to overcoming the barrier between thinking and doing, combining theory and practice to provide students the necessary tools for income generation through management and trade practices. The methodology of this work consists of a case study of the Technical Bazaar in Commerce as well as an experience report. The project integrating this course resulted in the insertion of the Institution into the external community, through integrated work among students, employees and community.
\end{abstract}

Keywords: Interdisciplinary Activities; Education of Adults; Method Integrative.

\title{
1. Introdução
}

Aborda-se nesse artigo as questões que perpassam as práticas interdisciplinares trabalhadas no Projeto Integrador com o Programa Nacional de Integração da Educação Profissional com a Educação Básica, na Modalidade de Jovens e Adultos (PROEJA) ${ }^{3}$ e a Formação Inicial e Continuada (FIC) $)^{4}$, que a 6 anos se efetiva com sucesso no Instituto Federal Farroupilha, campus Júlio de Castilhos. Esse projeto integrador começou a ser pensado a partir de reuniões de estudos das diretrizes e documentos bases do PROEJA, educação e trabalho, currículo integrado, viabilizar os Saberes dos alunos, metodologias, avaliação, contribuindo para a formação integral do educando entre o pensar e o fazer. Assim, para uma melhor aprendizagem é necessário buscarmos novas alternativas, principalmente na Educação Profissional Integrada a Educação Básica na Modalidade de Jovens e Adultos. Trabalhar de forma interdisciplinar, levando em conta as vivências dos alunos, valorizando suas habilidades, aproveitando suas experiências e seus conhecimentos, bem como seu ambiente de trabalho, deve ser levada em consideração. O Projeto Integrador busca aliar a teoria e a prática, essa prática tem o intuito de buscar novas formas de aprendizagem

A partir do momento em que se propõe trabalhar de maneira interdisciplinar, com planejamento e estudos, ouvindo sempre as necessidades dos educandos, obtém-se resultados satisfatórios. A gestão propõe reuniões frequentes, oportunizando estudos, planejamento e analisar temas inerentes ao PROEJA, o que, por conseguinte, possibilitou a troca de

\footnotetext{
${ }^{3}$ O PROEJA que tem por objetivo oferecer oportunidade da conclusão da educação básica, juntamente com a formação profissional àqueles que não tiveram acesso ao ensino médio na idade regular.

${ }^{4}$ O Art. $7^{\circ}$ da Lei 11.892/2008 destaca que são objetivos dos Institutos Federais “.[...] ministrar cursos de Formação Inicial e Continuada de trabalhadores, objetivando a capacitação, o aperfeiçoamento e a atualização de profissionais, em todos os níveis de escolaridade, nas áreas da educação profissional e tecnológica.
} 
experiências. Também verificamos a importância de termos um momento específico para trabalharmos no projeto integrador que foi desenvolvido pelas turmas do PROEJA e do FIC, que ocorre através das oficinas no decorrer do ano letivo. Objetivando assim, práticas em comércio, economia solidária e fomentar o empreendedorismo. Com os lucros arrecadados no Bazar realizarmos uma viagem de estudos, proporcionando o conhecimento de diferentes culturas, como também a integração entre professores e alunos do Eixo em Gestão de Negócios. Busca-se fundamentar pela proposta das Oficinas como um processo ativo de trabalho, integração e aprendizagem.

\section{Projeto integrador: práticas interdisciplinares efetivadas nas oficinas}

O PROEJA foi criado pelo decreto $n^{\circ} .5 .478$, de 24/06/2005, que expressou a vontade governamental de atender a uma demanda de Jovens e Adultos que são excluídos do sistema educacional, seja no ensino fundamental ou no ensino médio, tal proposta busca a formação humana desses cidadãos, como verificamos a seguir:

\footnotetext{
Com acesso ao universo de saberes e conhecimentos científicos e tecnológicos produzidos historicamente pela humanidade, integrada a uma formação profissional que permita compreender o mundo, compreender-se no mundo e nele atuar na busca de melhorias das próprias condições de vida e de construção de uma sociedade socialmente justa. A perspectiva precisa ser, portanto, de formação na vida e para a vida e não apenas de qualificação do mercado ou para ele." (Documento Base do PROEJA, 2006, p. 13).
}

Entendemos que a formação desses cidadãos se volta para processo que envolve a inclusão, pois está direcionada a esse elevado número de pessoas, que necessitam de uma qualificação profissional, muitos estão fora do contexto escolar, mas necessitam de melhor condições para o trabalho, buscam na Educação de Jovens e Adultos uma solução imediata para melhores oportunidades no mercado de trabalho, incentivando-os para que se tornem menos competitivos e mais confiantes do seu papel político e social.

Nessa linha do pensamento, são criados os Institutos Federais de Educação que veem com uma proposta de oferta de educação integrada ao público jovem e adulto, integrando a educação básica à formação profissional. Assim, o Documento Base do PROEJA, no que se refere ao currículo integrado o plano político pedagógico:

É uma possibilidade de inovar pedagogicamente na concepção de ensino médio, em resposta aos diferentes sujeitos sociais para os quais se destina, por meio de uma concepção que considera o mundo do trabalho e que leva em conta os mais diversos saberes produzidos em diferentes espaços sociais. Abandona-se a perspectiva 
estreita de formação para o mercado de trabalho, para assumir a formação integral dos sujeitos, como forma de compreender e se compreender no mundo (2007, p. 43).

Percebemos que o currículo integrado na modalidade PROEJA vem reforçar essas ideias de atrelar a escola às demais estâncias sociais, para que esse aluno consiga relacionar a escola com o mundo vivido, real. Nessa linha do raciocínio, as políticas educacionais públicas veem proporcionar a formação integral do educando, contribuindo:

\begin{abstract}
Para a integração social do educando, o que compreende o mundo do trabalho sem resumir-se a ele, assim como compreende a continuidade dos estudos. Em síntese, a oferta organizada se faz orientada a proporcionar a formação de cidadãos profissionais capazes de compreender a realidade social, econômica, política, cultural e do mundo do trabalho, para nela inserir-se e atuar de forma ética $\mathrm{e}$ competente, técnica e politicamente, visando à transformação da sociedade em função dos interesses sociais e coletivos especialmente os da classe trabalhadora (Documento Base, 2007, p.35).
\end{abstract}

Sobre o currículo, Moll (2010, p. 131) esclarece que a consolidação da democracia quanto ao acesso, permanência e aprendizagem na instituição escolar, deve estar assegurada pela "ampliação de oportunidades educativas pode colaborar para o enfrentamento de profundas desigualdades existentes no Brasil, bem como para a valorização da diversidade social e cultural que nos caracteriza e enriquece como nação". Nesse contexto, compreendemos que a escola é única oportunidade de conhecimento aos menos favorecidos, portanto, esse espaço vem promover a emancipação.

Afirmamos com essas práticas que a relação professor-aluno significa a convivência e a cumplicidade entre seres humanos mediada por um espaço chamado Escola. Entendemos que existem funções, papéis a serem desempenhados no processo ensino-aprendizagem. Onde as experiências pessoais vindas tanto do docente como do discente. Nessa linha de pensamento, segundo Demo "podemos acrescentar aqui, ao lado das ideias central de motivar um ambiente de trabalho em conjunto, a outra de aproveitar a experiência de cada um e de relacionar o que se aprende com a vida concreta.” (p. 23, 1996).

Há, por conseguinte, muita negociação a ser realizada, muita troca de experiências e vivências que irão amparar a expansão e compreensão das diversidades que, ao mesmo tempo, convergem para um objetivo que deve ser comum, o de aprender. Assim, nessa proposta do Projeto Integrador, compreendemos que a problematização, discussão é uma prática democrática, onde todos participam professores e alunos desse processo de aprendizagem, de acordo com Freire "ninguém educa ninguém, ninguém educa a si mesmo, os homens educamse entre si, mediatizados pelo mundo" (FREIRE, 2001, p. 68). Assim, busca-se novas formas de aprendizagem na Educação Profissional Integrada a Educação Básica na Modalidade de 
Jovens e Adultos, nesse processo trabalhar de forma interdisciplinar, proporcionar a prática da economia solidária e fomentar o empreendedorismo, favorecendo o desenvolvimento regional através do aprendizado profissional envolvendo alunos, servidores e comunidade em geral.

Portanto, no espaço escolar foram planejadas e realizadas as oficinas, respeitando todas as diversidades e as especificidades do educando, levando em consideração as práticas desenvolvidas nesta modalidade. Construir o Projeto Integrador de forma a contemplar as ansiedades dos educandos e educadores, como também proporcionar aos alunos espaços de diálogos, planejamento e apresentações de propostas para o trabalho das oficinas que acontecem decorrer do ano letivo.

Inicialmente, os alunos apresentaram os projetos dos produtos a serem confeccionados nas oficinas, foram organizados grupos para a apresentação das propostas, a ser pensada e criada pelos alunos, valorizando os seus saberes. Assim, em aula foi disponibilizada uma planilha, na qual os alunos descreveriam o que era necessário para confecção do produto, materiais, quantidade, custos e qual valor poderia ser comercializado, após a apresentação dos projetos os alunos e professores fizeram uma votação de quais produtos seriam produzidos nas oficinas que aconteceram no decorrer do ano letivo e posteriormente vendido no Bazar.

Compreendemos assim, que a sala de aula é um espaço democrático, libertador, ao mesmos tempo que objetiva as expressões humanas, as racionaliza para que possam ser observadas, pensadas e redimensionadas, promovendo a aceitação de repensar como parte dinâmica da vida, e as novas experiências como elemento positivo que amplia a percepção dos educandos, promovendo a autonomia, de discutir, problematizar e principalmente de partilhar seus saberes e vivências, dando significados aos conteúdos propostos.

Esse espaço educativo deve ser formado por valores éticos, sociais, ambientais e políticos, mantendo sua dignidade e desempenhando ações junto à sociedade. Nesse processo, a escola é um:

lugar de pessoas e de relações, é também um lugar de representações sociais. Como instituição social ela tem contribuído tanto para a manutenção quanto para a transformação social. Numa visão transformadora ela tem um papel essencialmente crítico e criativo (GADOTTI, 2007, p. 11).

Nesse espaço educacional, em que os educandos se sentem valorizados, integrados, participando ativamente de todo o processo de ensino aprendizagem. Nesse sentido, Silva (2010) traz o currículo e a educação de uma forma ampla, afirmando que os indivíduos sofrem influência de outros ambientes da sociedade, no espaço escolar, fazendo que o 
currículo não seja neutro e nem esvaziado de significados, nesse sentido, o discurso da neutralidade é algo impensável, ou seja, somos seres sociais e nos desenvolvemos socialmente com os outros, estamos em constante evolução.

Assim, incentiva-se as meninas a desfilarem, cada uma colaborando com as suas habilidades, promovendo a autoestima do grupo, com faixa etária de 18 a 67 anos, valorizando a participação de todos, os professores participam também do desfile, promovendo ainda mais a integração. A caminhada das oficinas ao Bazar é permeada de ações onde todos têm a oportunidade de se envolver em todo o processo: pensa, criar, analisar, produzir e mostrar o produto final através do desfile, como também da exposição desses produtos para a comercialização, como afirma Dewey (1972), os saberes devem fazer sentido para á vida dos alunos, como também propiciar experiências democráticas no espaço escolar, assim o aluno se desenvolve socialmente, a escola deve ser entendida como comunidade, deve-se pensar em sociedade como um todo, portanto, um currículo que tenha significado para a vida social dos alunos.

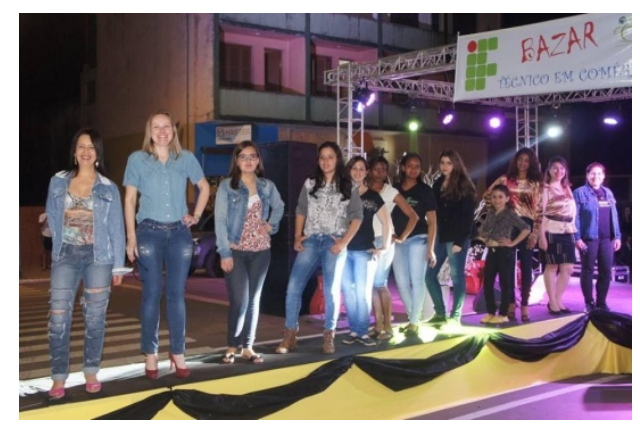

Imagem 1 - Desfile em Tupanciretã, alunos e professores. Fonte: Autoras (2016)

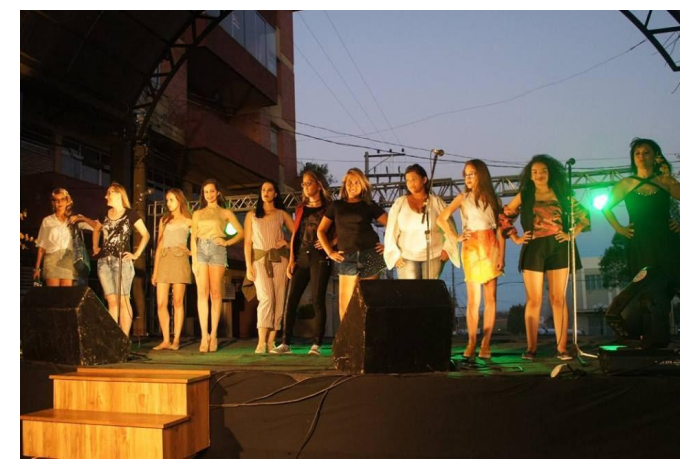

Imagem 2 - Desfile em Júlio de Castilhos, alunas e professores.

Fonte: Autoras (2017) 


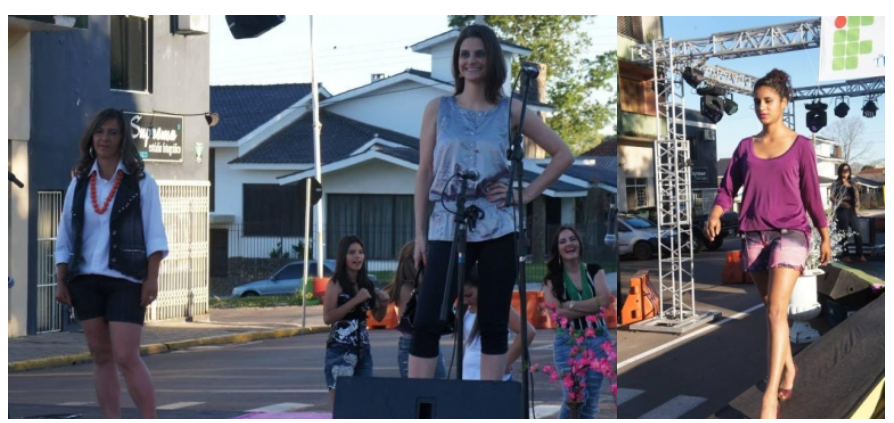

Imagem 3,4 e 5 - Desfile em Tupanciretã, alunas e professores.

Fonte: Autoras (2018)

A proposta desse projeto é repensada a cada ano, alterando as oficinas, mas, sempre permanecemos com a oficina de customização de roupas, pois é através dessa produção que temos materiais para o desfile. Assim, percebe-se que o professor é fundamental, pois é ele quem vai nortear o trabalho inicial em sala de aula, a pesquisa, os grupos de trabalho, os projetos, as ações futuras, construindo um espaço democrático para que os alunos saibam se posicionarem, sendo autônomos e críticos. Portanto, acreditamos que "as instituições escolares possuem possibilidades e autonomia suficiente para que outras visões de mundo, ideias, conceitos e práticas alternativas possam enfrentar as dominantes e oficiais" (TORRES, p. 239, 2013).

Nesse sentido, se faz necessário levar em consideração as vivências e experiências do educando, buscando nesse contexto o que realmente tenha significado, as oficinas representam um processo ativo de trabalho, integração e aprendizagem, abordando conteúdos e práticas interdisciplinares, valorizando os saberes, processo onde educando e educadores compartilham experiências e aprendizagens. Reforçado por Freire (1996, p. 22) que cabe ao professor se assumir como sujeito da produção do saber que, "se convença definitivamente de que ensinar não é transferir conhecimento, mas criar a possibilidade para a sua produção e construção". Não se pode ser um professor crítico e democrático agindo de forma mecânica, sem desafiar seus alunos a acreditarem que são capazes de produzirem e pensarem criticamente.

Dessa forma, essa prática contribuirá para que professores e alunos se sintam parte do processo ensino aprendizagem. Diante desse contexto, os Institutos Federais de Educação, Ciência e Tecnologia, devem contribuir para a formação humana e profissional, proporcionando a inclusão social. Ainda nas palavras de Freire (1996) para entendermos a dimensão do currículo em toda a sua amplitude, deve-se ir além das diferenças entre os níveis formal, oculto e vivido.

Lopes e Macedo afirmam quanto ao currículo que: 
O currículo é uma produção cultural por estar inserido nessa luta pelos diferentes significados que conferimos ao mundo. O currículo não é um produto de uma luta fora da escola para significar o conhecimento legítimo, não é uma parte legitimada da cultura que é transposta para a escola, mas é a própria luta pela produção de significado (2011, p. 93).

Compreendemos que as ações que realizamos na escola devem fazer sentido aos educandos, por esse viés o Projeto Integrador propõe aliar a teoria à prática, com atividades interdisciplinares contemplando as três turmas de PROEJA Técnico em Comércio e as três turmas FIC, uma na cidade de Tupanciretã e uma em Júlio de Castilhos, onde as oficinas são ofertadas nesses locais, contemplamos no nosso espaço do IFFar uma turma de FIC, que realiza as oficinas juntamente com o PROEJA, as oficinas ofertadas: artesanato, bijuterias, materiais reciclados de pneus, paletes, jornais, roupas customizadas, móveis em madeira, almofadas, ornamentação de cuias, gestão do bazar, entre outras, proporcionando troca de experiências e saberes, como também contribuir na formação integral entre o pensar e o fazer. Fotos abaixo.

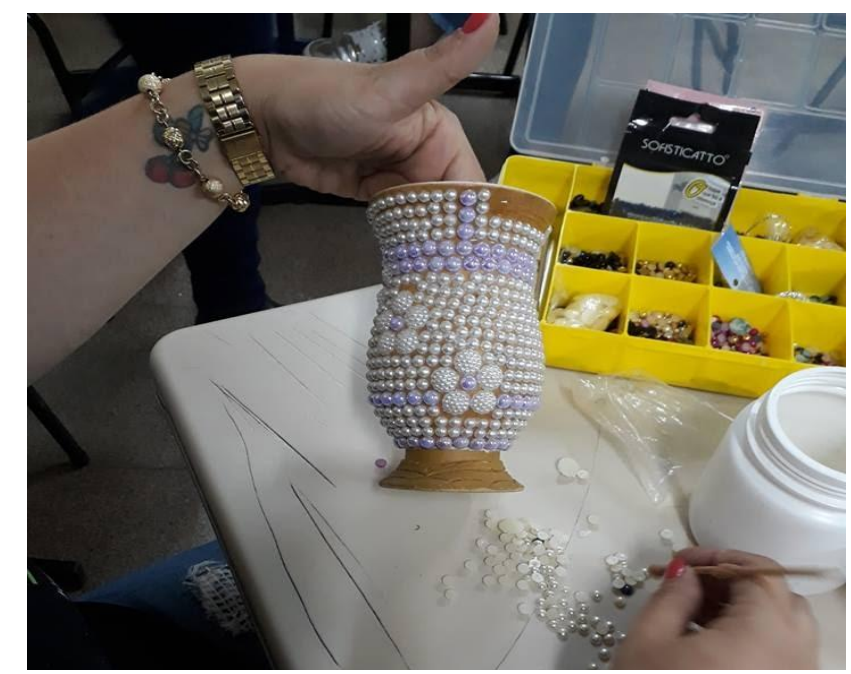

Imagem 6 - Produção das oficinas, Cuias ornamentadas. Fonte: Autoras (2018). 


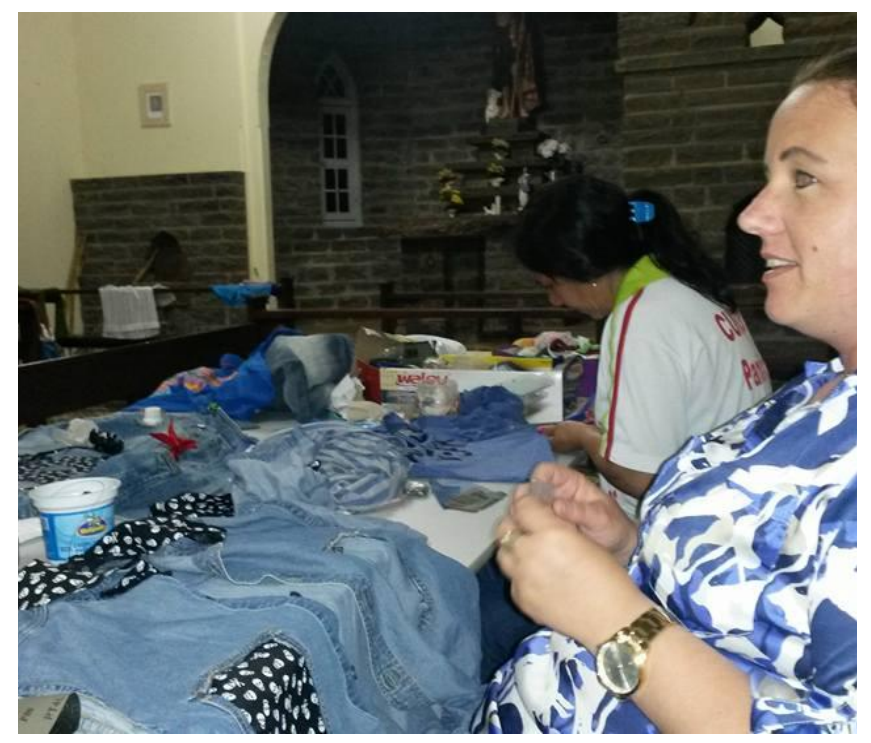

Imagem 7 - Oficina de customização, 2016. Fonte: Autoras (2018).

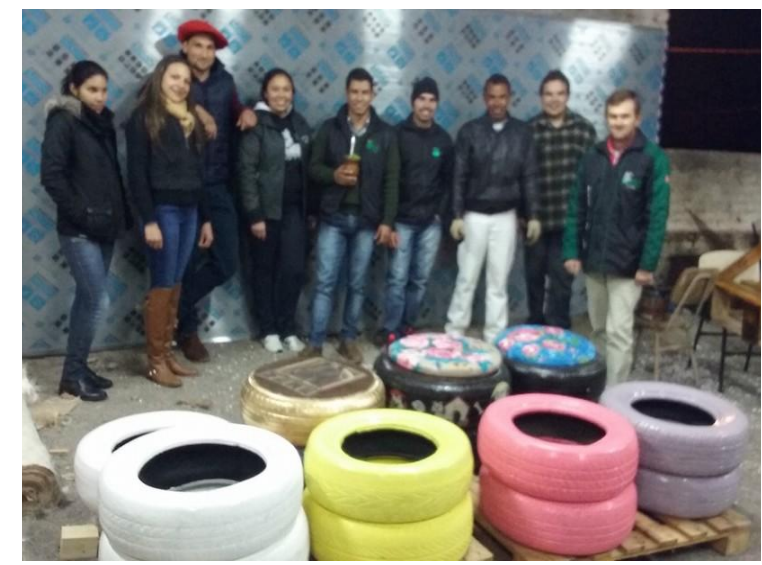

Imagem 8 - Oficina de reciclagem de pneus, confecção de Puffs, 2016. Fonte: Autoras (2016).

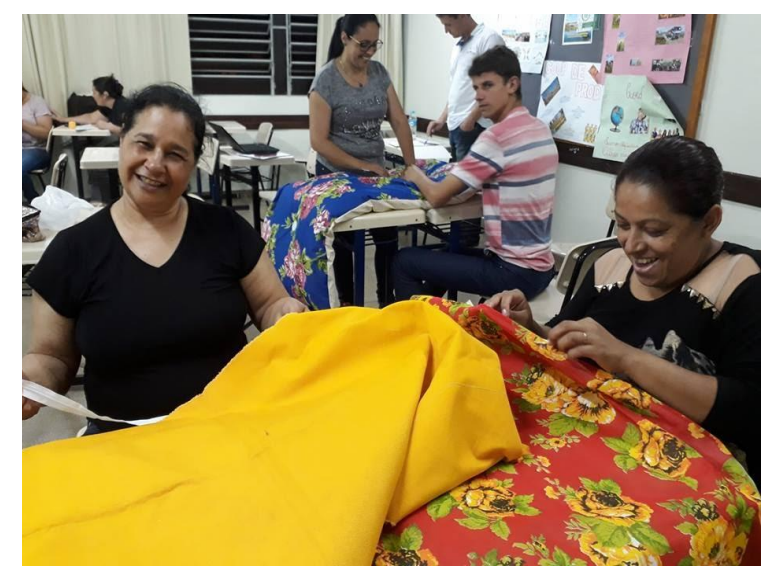

Imagem 9 - Oficina de costura, confecção de almofadas para os sofás de paletes. 2018 Fonte: Autoras (2018). 


\section{RELACult - Revista Latino-Americana de Estudos em Cultura e Sociedade \\ RevistaLatinoamericana de EstudiosenCultura y Sociedad | Latin American Journal of Studies in Culture and Society}

V. 05, ed. especial, abr., 2019, artigo no 1241 | claec.org/relacult | e-ISSN: 2525-7870

Após serem confeccionadas os produtos pelos alunos e professores nas oficinas, chega o dia esperado do "Bazar", esse espaço é organizado para mostrar a comunidade o que os alunos produziram no decorrer do ano, como também é comercializado os produtos, nesse dia se organiza um desfile de modas com as roupas customizadas e bijuterias confeccionadas nas oficinas, onde os modelos são os alunos e professores. O Bazar ocorre um ano em Júlio de Castilhos e outro em Tupanciretã. Objetiva-se assim, organizar e realizar o Bazar com o Desfile de Modas, para a socialização como também para a comercialização desses produtos. Participam também do evento artistas da comunidade externa, show artísticos, grupos de danças, capoeira, entre outros. O êxito do Projeto se dá com o comprometimento de todos. Abaixo fotos dos shows artísticos.

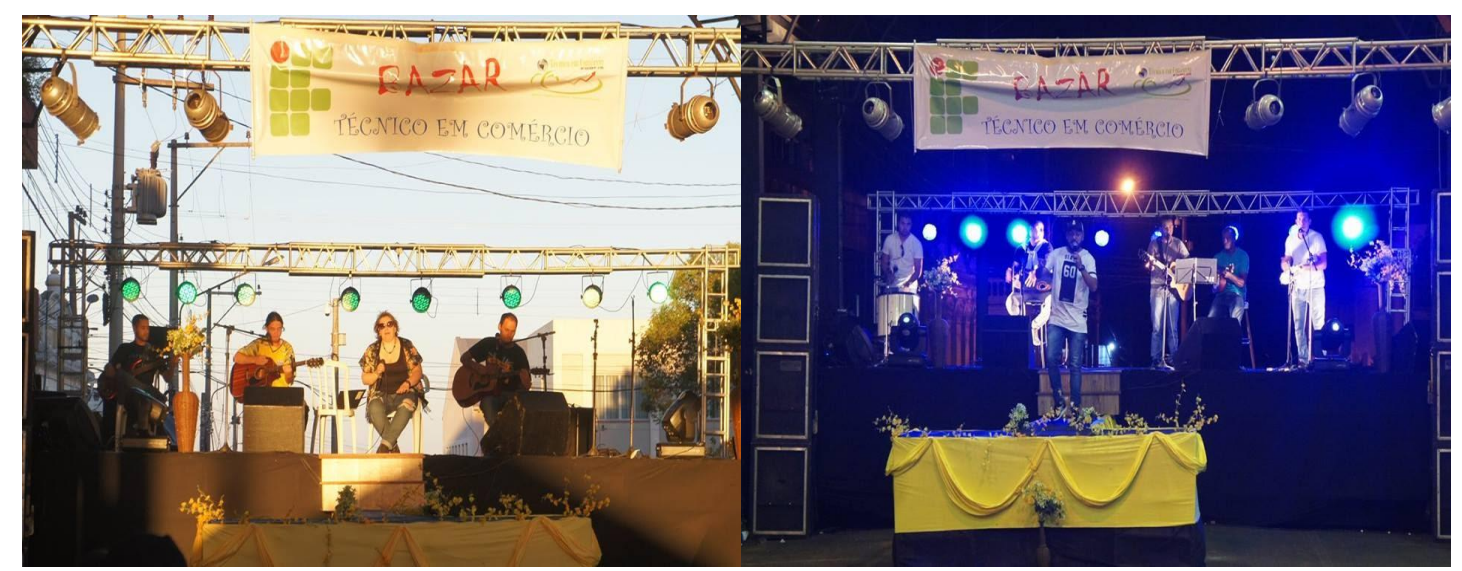

Imagem 10 e 11 - Apresentação show artístico com bandas dos alunos do curso de Administração, Bazar 2016, Tupanciretã Fonte: Autoras (2016).

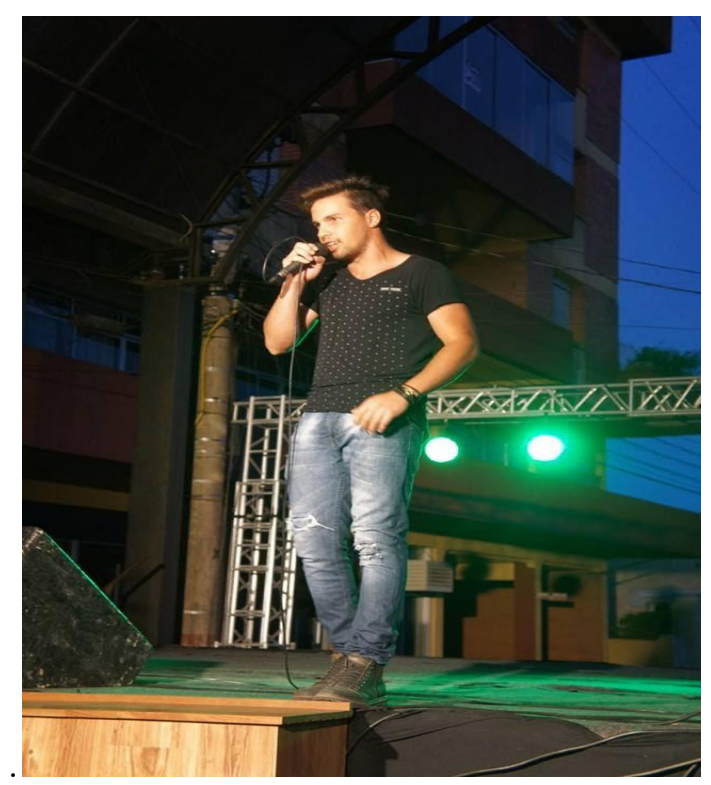

Imagem 12 - Apresentação artística, aluno do PROEJA, Bazar 2018. Fonte: Autoras (2018). 


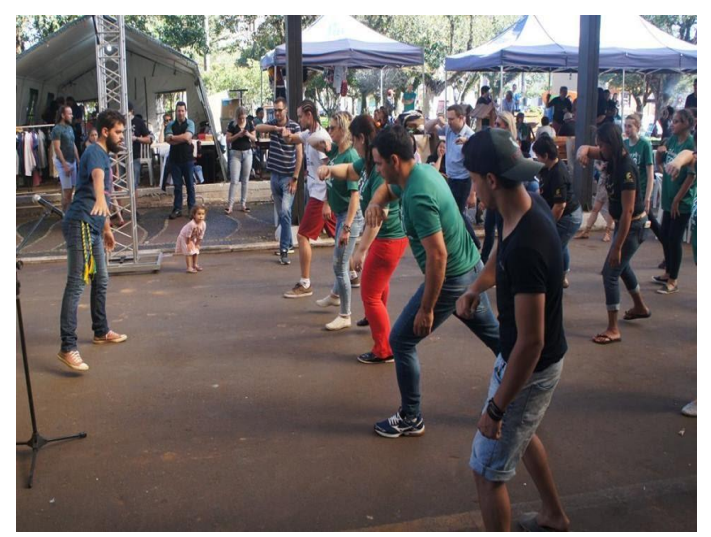

Imagem 13-Apresentação do grupo de capoeira do IFFar-JC. Bazar 2017 Fonte: Autoras (2017).

Através do Projeto Integrador do Eixo em Gestão de Negócios do IFFar - Júlio de Castilhos, vem reafirmar a Missão da Instituição, de "formar cidadãos críticos, autônomos e empreendedores, comprometidos com o desenvolvimento sustentável e um papel ativo na sociedade em prol do coletivo", com essa finalidade foram criados os Instituto Federal de Educação, Ciência e Tecnologia Farroupilha - IF Farroupilha, através da lei no 11.892, de 29 de dezembro de 2008. Permeando a educação superior, básica e profissional, pluricurricular e multicampi, especializada na oferta de educação profissional e tecnológica nas diferentes modalidades de ensino, tendo como base a conjugação de conhecimentos técnicos e tecnológicos com a sua prática pedagógica.

Além disso, acredita-se, que "a educação não corrige necessariamente as estruturas e os comportamentos desiguais, mas poderia chegar a ser um importante mecanismo se os cidadãos e cidadãs pudessem desenvolver as suas capacidades de crítica e de luta por uma sociedade mais justa e democrática" (SANTOMÉ, 2007, p 160). Pois acreditamos que os Institutos Federais ocupam espaços fundamentais na constituição e desenvolvimento local e regional.

\section{Conclusão}

Assim, avaliamos o Projeto Integrador de grande valia no que diz respeito a formação integral do ser humano. Como professores, sentimo-nos motivados, felizes com os resultados alcançados no comprometimento e cumplicidade do trabalho em equipe. Pois em um contexto permeado pela necessidade de adequação do currículo às necessidades do PROEJA, concluímos que esse currículo deve primar pelo trabalho como fator primordial para a 
constituição humana, como também a uma participação crítica e reflexiva na sociedade. Assim se propõe a elaboração de novas propostas levando em consideração as reais necessidades dos educandos. A discussão é iniciada com a importância que tem a educação para o desenvolvimento da sociedade.

\section{Referências}

BARCELOS, V. Educação de Jovens e Adultos: currículo e práticas pedagógicas. Rio de Janeiro, Petrópolis: Vozes, 2010.

BRASIL. Ministério da Educação. Políticas Públicas para a educação profissional e tecnológica. MEC: Brasília, DF, 2004b.

. Decreto n.5.478 de 24 de junho de 2005. Institui no âmbito das Instituições Federais de Educação Tecnológica, o Programa de Integração da Educação Profissional ao Ensino Médio na Modalidade de Educação de Jovens e Adultos (PROEJA). Brasília, DF, 2005.

. Decreto n.5.840 de 13 de julho de 2006. Institui, no âmbito federal, o Programa Nacional de Integração Profissional com a Educação Básica na Modalidade de Educação de Jovens e Adultos - PROEJA, e dá outras providências. Brasília, DF, 2006.

2006.

. Ministério da Educação. PROEJA - Documento Base. MEC, SETEC: Brasília,

. Ministério da Educação. Secretaria da Educação Profissional e Tecnológica. Educação Profissional Técnica de Nível Médio Integrada ao Ensino Médio - Documento Base. Brasília, 2007.

CIAVATTA; M. A formação integrada: a escola e o trabalho como lugares de memória e de identidades. In. FRIGOTTO, G.; CIAVATTA, M.; RAMOS, M.; (Orgs.). Ensino Médio Integrado: concepções e contradições. São Paulo: Cortez, 2005.

DEMO, P. Educar pela pesquisa. $3^{\text {a }}$ ed. Campinas, São Paulo, Brasil: Autores Associados. 1998.

DEWEY, J. Vida e Educação. São Paulo: Melhoramentos, 1972.

FREIRE, P. Pedagogia do Oprimido. Rio de Janeiro: Paz e Terra, 2001.

FREIRE, P. Pedagogia da autonomia: saberes necessários à prática educativa. 31. ed. São Paulo: Paz e Terra, 1996.

GADOTTI, M. A Escola e o Professor: Paulo Freire e a paixão de ensinar. 1 ed. São Paulo: Publisher Brasil, 2007.

LOPES, A. C.; MACEDO, E. F. Teorias de currículo. São Paulo: Cortez, 2011. 
MOLL, J. Educação Profissional e Tecnológica no Brasil Contemporâneo: desafios, tensões e possibilidades. Porto Alegre: Artmed, 2010.

SANTOMÉ, J. T. A educação em tempos de neoliberalismo. Porto Alegre: Artemed, 2007.

SILVA, T. T. Documentos de Identidade: uma introdução as teorias do currículo. - 3 ed. Belo Horizonte: Editora Autêntica, 2010.

TORRES, S. J. Currículo escolar e justiça social: o cavalo de troia da educação. Porto Alegre: Penso, 2013 